\title{
New perspectives in regional anesthesia: the use of ultrasound - past, present, and future
}

Peter Marhofer MD, Harald Willschke MD, Manfred Greher MD, Stephan Kapral MD

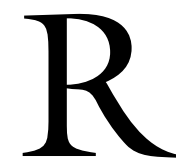

EGIONAL anesthesia is enjoying a renaissance. New pharmacological agents (e.g. pure isomers - ropivacaine, additives - clonidine) and a broad spectrum of techniques (both single injection and continuous catheter techniques) allow anesthesiologists to facilitate most surgical procedures with regional anesthesia alone or in combination with a general anesthetic. Nevertheless, a huge number of different techniques for blockade (e.g., for the psoas compartment block more than 20 puncture sites are described) are confusing and may be a reason that skepticism remains regarding the broad use of regional anesthesia in daily clinical practice. Some anesthesiologists still continue to use techniques that do not allow precise localization of targeted neuronal structures or may expose patients to unnecessary risk, such as loss of resistance techniques, blind infiltration, and the deliberate elicitation of paresthesia. In this regard it is no wonder that, when strong criteria are used, the success rates of some regional anesthetic techniques are rather low.

The use of ultrasonographic guidance offers the advantage of performing blocks with direct visualization of all involved anatomical structures. Despite our enthusiasm for the use of ultrasound in regional anesthesia, most of the initial findings with this new application of ultrasound technology need further scientific evaluation and validation. This point was recently made in an editorial by Denny and Harrop-Griffiths. ${ }^{1}$ For example, outcome studies examining the relative safety of various techniques are extremely difficult to perform because of the rarity of serious adverse events and the necessity for large sample sizes. Until these studies are done, we will have to rely on the experiences, expert opinion, and direction of a few experts in the field.

This article reviews the history and the present status of ultrasonography in regional anesthesia, one of the most exciting technical developments during the past years in our speciality, and tries to describe a view for the future.

\section{History and presence of ultrasonography in regional anesthesia}

In 1978 La Grange et al. reported the use of a Doppler flow ultrasound detector for facilitating supraclavicular brachial plexus block, ${ }^{2}$ which was, to our knowledge, the first paper describing the indirect use of ultrasonography in regional anesthesia. The main limitation of more advanced applications of ultrasound at that time was the inability to obtain high-resolution 2D images. In 1994 Kapral et al. published the first paper using direct ultrasonographic visualization for a regional anesthetic method (supraclavicular brachial plexus block) including the direct observation of the spread of local anesthetic. ${ }^{3}$ Thenceforward, in principle, ultrasonographic guidance for different regional anesthetic methods was possible but the quality of the views remained poor due to inadequate resolution with the ultrasound technology used at that time.

In 1994, referring to the need for more precision in regional anesthesia, Winnie stated, "Sooner or later someone will make a sufficiently close examination of the anatomy involved, so that exact techniques will be developed". ${ }^{4}$ In the last decade, our group has worked hard to realize this vision. During this time improvements in ultrasonographic technology facilitated investigations in ultrasonographic visualization of nerve structures. This made nearly all regional anesthetic techniques under ultrasonographic guidance possible. Five scientific study groups had significant parts in the implementation of ultrasonography for regional anesthesia and pain medicine in clinical practice. Dr. Thomas Grau and his colleagues from Germany have done some fundamental research concerning neuraxial ultrasound in adults and children. Dr. Vincent Chan and colleagues, from Canada, have significantly advanced the use of ultrasound in regional anesthesia. Dr. Schafhalter-Zoppoth and his colleague Dr. Grey, from San Francisco, have made similar contributions. Significant findings in pain therapy have been made by Dr. Michele Curatolo togeth-

From the Department of Anaesthesia and Intensive Care Medicine, Medical University of Vienna, Vienna, Austria.

Address correspondence to: Dr. Peter Marhofer, Professor of Anaesthesia and Intensive Care Medicine, Medical University of Vienna, Department of Anaesthesia and Intensive Care Medicine, Waehringer Guertel 18-20, A-1090 Vienna, Austria. Phone: +43 1404004107 ; Fax: +43 140400 4028; E-mail: peter.marhofer@meduniwien.ac.at; Homepage: www.sono-nerve.com 
er with Dr. Urs Eichenberger, from Switzerland. Dr. Manfred Greher, from our group in Vienna, introduced the use of ultrasound for some specific indications in chronic pain therapy. Our study group (Vienna) is led by Dr. Stephan Kapral.

During the past ten years the interest of anesthesiologists around the world for ultrasonography in regional anesthesia has continuously increased. Major barriers to the implementation of ultrasound in regional anesthesia into daily clinical practice are the expense of the equipment and the need for specialized training.

\section{Ultrasonographic equipment}

Ultrasound-guided nerve blocks can be performed with most modern ultrasound systems. They should be equipped with software to visualize both superficial tissues and musculoskeletal structures. High-resolution ultrasound (HRUS) systems come with software that allows optimized visualization of tissue contrast. Colour and pulsed-wave Doppler imaging helps to identify vessels in proximity to nerves. If the equipment includes a high-capacity hard disk the images can be stored for future reference. Short film sequences can then be stored and transferred to disc via a CD or DVD burner. Files can be stored in RAW-data, JPG, BMP or MPG4 formats.

Visualizing nerves by sound waves requires the use of high frequencies to offer high-resolution images. However, the higher the frequency the smaller the penetration depth. Most nerve block applications require frequencies in the range of 10 to $14 \mathrm{MHz}$. Broad-band transducers covering a bandwidth of 5 to $12 \mathrm{MHz}$ or 8 to $14 \mathrm{MHz}$ offer excellent resolution of superficial structures in the upper extremity, and good penetration depth in the lower extremity.

Ultrasonographic equipment having the above requirements has been available for about five years. The development of extremely portable high-resolution ultrasound equipment with high frequency probes at reasonable cost has been an important industrial contribution that has helped spread the use of ultrasonographic-guided regional anesthesia. Specially designed equipment, which is not Windows-based, seems to be useful in daily clinical practice due to excellent stability of the systems and fast booting times. High-resolution ultrasonography, which is a prerequisite for visualization of nerve structures, is possible with the more portable ultrasonographic equipment. In the near future 15 $\mathrm{MHz}$ probes will be available for these systems. Eventually, therefore, there will only be slight differences between portable equipment and the highest-end high-cost ultrasound machines.

\section{Specific recommendations for education}

Additional education to perform ultrasonographicguided regional anesthetic blocks is necessary. Handson workshops are performed in several countries (see below). Hands-on workshops are the best tool by which to learn the theoretical and practical aspects of this technique. Regional anesthesia cadaver workshops are held in Innsbruck / Tyrol in Austria. Dr. Christoph Huber, the promoter of these workshops was a pioneer in the development of new techniques in regional anesthesia and recognized the importance of including ultrasonography in these workshops. The group around Thomas Grau from Germany, in 2002, organized workshops in Heidelberg / Germany, and Barry Nicholls followed in 2003 with workshops in London. Per Arne Lönnqvist from the Karolinska Institute in Stockholm / Sweden organizes workshops for Scandinavian anesthesiologists. Our study group organizes workshops in Vienna in German and in English. Dr. Vincent Chan has organized workshops in Canada. Hence, theoretical and practical education in the field is readily available around the world. Initial close supervision for beginners in the use of ultrasound for regional anesthesia is also recommended. This is a major problem at the present time due to a lack of experienced specialists trained in the field.

\section{Some specific considerations and notes about ultra- sonography for regional anesthesia and pain medicine} After ten years of intensive scientific evaluation, most of the regional anesthetic techniques have been studied. The promotion of ultrasound for regional anesthesia cannot be made on the basis of enhanced safety at this time ${ }^{1}$ but efficacy has been shown to be equivalent to or better than traditional techniques. Several thousand patients would be necessary to perform clinical studies regarding patient safety and, therefore, we will have to adopt the technique based on its clear advantage in illustrating the anatomical structures of interest. These anatomical structures include blood vessels, muscles, tendons and our target for regional anesthesia, nerves. All of these structures are visible using HRUS and they can be followed over nearly their entire course. Even for structures not accessible or poorly accessible with ultrasound because of their depth or structural interference from bone (e.g., psoas compartment block, epidural space), the anatomy can be visualized to such an extent that important clues are obtained that help facilitate performance. ${ }^{5}$

The most important and unique advantage of ultrasonographic-guided regional anesthesia is the ability to directly observe spread of local anesthetic solution. Traditional approaches to discriminatory nerve block- 
TABLE Summary of ultrasonographic-guided regional anesthetic techniques

\begin{tabular}{|c|c|c|}
\hline Technique & Ultrasonographic probe & Technique \\
\hline $\begin{array}{l}\text { Brachial plexus blocks } \\
\text { Interscalene }\end{array}$ & Linear, $\geq 10 \mathrm{MHz}$ & $\begin{array}{l}\text { Transverse view, puncture along the short axis, needle reposition necessary to } \\
\text { block the C } 8 \text { and } \mathrm{Tl} \text { roots }^{16}\end{array}$ \\
\hline Supraclavicular & Linear, $\geq 10 \mathrm{MHz}$ & Transverse view, in-line technique ${ }^{3,17}$ \\
\hline (Lateral) infraclavicular & Linear, $8 \mathrm{MHz}$ & Transverse view, puncture along the short axis ${ }^{18,19}$ \\
\hline Axillary & Linear, $\geq 10 \mathrm{MHz}$ & Transverse view, puncture along the short axis, multi-injection technique ${ }^{20}$ \\
\hline Distal nerve blocks & Linear, $\geq 10 \mathrm{MHz}$ & $\begin{array}{l}\text { Transverse view, puncture along the short axis }{ }^{21} \\
\text { Lumbosacral plexus blocks }\end{array}$ \\
\hline Psoas compartment & Sector, $2-5 \mathrm{MHz}$ & $\begin{array}{l}\text { Transverse view }\left(90^{\circ} \text { angle to the vertebral column }\right) \text {, in-line technique [nerves } \\
\text { in adults sometimes not visible - lumbar plexus between the middle and posteri } \\
\text { or third of the psoas muscle }]^{5,22,23}\end{array}$ \\
\hline Sciatic - infragluteal & Linear, $5-10 \mathrm{MHz}$ & Transverse view, puncture along the short axis \\
\hline Sciatic - midfemoral & Linear, $5-10 \mathrm{MHz}$ & Transverse view, puncture along the short axis \\
\hline Sciatic - popliteal & Linear, 5-10 MHz & $\begin{array}{l}\text { Transverse view, in-line technique from lateral side or puncture along the short } \\
\text { axis posteriorly }{ }^{24}\end{array}$ \\
\hline 3 -in-1 block & Linear, $\geq 10 \mathrm{MHz}$ & Transverse view, puncture along the short axis ${ }^{25,26}$ \\
\hline Saphenous & Linear, $\geq 10 \mathrm{MHz}$ & Transverse view, puncture along the short axis \\
\hline Ilioinguinal & Linear, $\geq 10 \mathrm{MHz}$ & Transverse view, puncture along the short axis or in-line technique \\
\hline Neuraxial & Linear, $5-10 \mathrm{MHz}$ & $\begin{array}{l}\text { Longitudinal view from paramedian, puncture from median, reduced ultrasono- } \\
\text { graphic visibility in adults compared with children }{ }^{27-37,38}\end{array}$ \\
\hline
\end{tabular}

ade have focused on the position of the block needle relative to the nerve. It has been assumed that precise placement of the block needle close to the nerve will ensure adequate blockade. However, that may not be the case as blockade is variable even when good motor endpoints using nerve stimulators are obtained. Ultrasound provides an explanation for this observation. Ultrasound allows the direct visualization of the spread of local anesthetic. If local anesthetic spreads to cover the entire nerve blockade is assured. Despite close proximity of the needle to the nerve, if local anesthetic spread is incomplete, blockade may not occur or will be significantly delayed. It is important, for efficacy and safety reasons, for anesthesiologists to become familiar with this concept. It is clear that it is not simply the proximity of the tip of the needle to the nerve, but the actual spread of local anesthetic solution that is responsible for conduction blockade of the nerve! Ultrasonography is the only tool with which we are able to observe the spread of local anesthetic in an easy and non-invasive way.

It may be important, as well, to observe the body as well as the tip of the needle in order to avoid damage of adjacent structures (e.g., blood vessels, other nerves, or cervical pleura during supra- or infraclavicular brachial plexus block). The learning curve for achieving the manual and intellectual skills necessary to achieve these goals has not been described. However, proficiency can be rapidly obtained.

\section{A short review of the different techniques}

The aim of this article is not to attempt to describe every regional anesthetic technique possible under ultrasonographic guidance. Nevertheless, this article would be incomplete without a short review of the current status of the different techniques.

Our technique to block nerve structures is based on a ten-year period of scientific and practical development. It may differ in detail from the techniques used by other experts. The differences are in the fine details and it is not clear if one technique is preferable to another. During the past decade our understanding of the anatomy has increased and, consequently, we have developed and adjusted the different approaches for brachial and lumbosacral plexus block. Most of the blocks are performed with a cross-sectional technique, which means that the cannula is visualized in the ultrasonographic short axis view. This allows a shorter skinnerve distance compared with the so-called in-line technique where the cannula is introduced along the long axis relative to the probe.

The ideal qualities a needle must have to maximize visualization with ultrasound are not known. Schafhalter-Zoppoth et al. investigated the ultrasonographic visualization of different needles under invitro conditions using a gelatine phantom. ${ }^{6}$ They found that larger diameter needles with a Hustead needle tip when used with a metal guide wire maximized visualization, particularly when visualized with 
a long-axis view (i.e., transducer parallel to the long axis of the needle with a shallow trajectory angle).

We use insulated needles with specially designed facette tips (to reduce the chance of nerve injury) and an immobile needle technique (popularized by Winnie) that relies on an operator (the operator is responsible for securely positioning the needle) and an assistant (the assistant is responsible for the injection). Industry is trying to develop special needles with improved visibility. The future will show if they find solutions that provide an optimal balance between proper visibility and reduced artefact.

The Table shows a summary of our repertoire of ultrasonographic-guided regional anesthetic techniques with links to the current literature. Useful review articles are recently published articles from Kapral et al., ${ }^{7,8}$ Grau et al., ${ }^{9}$ Perlas et al., ${ }^{10}$ Rapp et al. ${ }^{11}$ and Marhofer et al. ${ }^{12}$

Ultrasonographic guidance techniques have also been investigated for chronic pain therapy. Stellate ganglion blocks ${ }^{13}$ and, most recently lumbar facette nerve blocks ${ }^{14,15}$ are safely and easily performed by using ultrasonographic guidance. Extremely low amounts of local anesthetic are used for these blocks. They are, therefore, excellent examples of the precision of ultrasonographic guidance.

\section{The future of ultrasonography in regional anesthesia}

There is no doubt that ultrasonography offers advantages in nearly all regional anesthetic techniques compared with conventional, landmark-based techniques. The concept of direct visualization of all involved anatomical structures and the observation of the spread of local anesthetic by ultrasonography is convincing. On the other hand, there is also no doubt that we are just at the beginning of our learning curve with this technique. As it took a long time to evolve from Moore's theorem "No paresthesias - No anesthesia" it will take time to convince the regional anesthetic community of the usefulness of ultrasonography in regional anesthesia. Further excellent clinical papers in that field are necessary. Portable ultrasound equipment with high frequency probes and appropriate software is available at relatively low prices and it seems that there is no end to the technical development possible.

The use of ultrasound in regional anesthesia requires a commitment to improving patient care. That commitment will necessitate an investment in equipment, personnel, and time.

\section{References}

1 Denny NM, Harrop-Griffiths W. Editorial I: Location, location, location! Ultrasound imaging in regional anaesthesia. Br J Anaesth 2005; 94: 1-3.

2 La Grange P, Foster PA, Pretorius LK. Application of the Doppler ultrasound bloodflow detector in supraclavicular brachial plexus block. Br J Anaesth 1978; 50: 965-7.

3 Kapral S, Krafft P, Eibenberger K, et al. Ultrasoundguided supraclavicular approach for regional anesthesia of the brachial plexus. Anesth Analg 1994; 78:

507-13.

4 Winnie AP BP, Hoakansson L. Plexus Anaesthesia: Perivascular Techniques of Brachial Plexus Blocks. Revised Edition. Philadelphia: Saunders; 1994.

5 Kirchmair L, Entner T, Wissel J, et al. A study of the paravertebral anatomy for ultrasound-guided posterior lumbar plexus block. Anesth Analg 2001; 93: 477-81.

6 Schafbalter-Zoppoth I, McCulloch CE, Gray AT. Ultrasound visibility of needles used for regional nerve block: an in vitro study. Reg Anesth Pain Med 2004; 29: 480-8.

7 Kapral S, Marbofer P, Gran T. Ultrasound in local anaesthesia. Part I: technical developments and background (German). Anaesthesist 2002; 51: 931-7.

8 Kapral S, Marhofer P. Ultrasound in local anaesthesia. Part II: ultrasound-guided blockade of peripheral nerve channels (German). Anaesthesist 2002; 51: 6-14.

9 Gran T, Conradi R, Martin E, Motsch J. Ultrasound and local anaesthesia. Part III: ultrasound and neuroaxial local anaesthesia (German). Anaesthesist 2003; 52: 68-73.

10 Perlas A, Chan VW, Simons M. Brachial plexus examination and localization using ultrasound and electrical stimulation: a volunteer study. Anesthesiology 2003; 99: 429-35.

11 Rapp HJ, Gran T. Ultrasound imaging in pediatric regional anesthesia. Can J Anesth 2004; 51: 277-8.

12 Marhofer P, Greher M, Kapral S. Ultrasound guidance in regional anaesthesia. Br J Anaesth 2005; 94: 7-17.

13 Kapral S, Krafft P, Gosch $M$, et al. Ultrasound imaging for stellate ganglion block: direct visualization of puncture site and local anesthetic spread. A pilot study. Reg Anesth 1995; 20: 323-8.

14 Greher M, Kirchmair L, Enna B, et al. Ultrasoundguided lumbar facet nerve block: accuracy of a new technique confirmed by computed tomography. Anesthesiology 2004; 101: 1195-200.

15 Greher M, Scharbert G, Kamolz LP, et al. Ultrasoundguided lumbar facet nerve block: a sonoanatomic study of a new methodologic approach. Anesthesiology 2004; 100: 1242-8.

16 Chan VW. Applying ultrasound imaging to interscalene brachial plexus block. Reg Anesth Pain Med 2003; 28: 340-3.

17 Chan VW, Perlas A, Rawson R, Odukoya O. 
Ultrasound-guided supraclavicular brachial plexus block. Anesth Analg 2003; 97: 1514-7.

18 Greher $M$, Retzl G, Niel P, et al. Ultrasonographic assessment of topographic anatomy in volunteers suggests a modification of the infraclavicular vertical brachial plexus block. Br J Anaesth 2002; 88: 632-6.

19 Marhofer P, Sitzwohl C, Greher M, Kapral S. Ultrasound guidance for infraclavicular brachial plexus anaesthesia in children. Anaesthesia 2004; 59: 642-6.

20 Retzl G, Kapral S, Greher M, Mauritz W. Ultrasonographic findings of the axillary part of the brachial plexus. Anesth Analg 2001;92: 1271-5.

21 Bacigalupo L, Bianchi S, Valle M, Martinoli C. Ultrasonography of peripheral nerves (German). Radiologe 2003; 43: 841-9.

22 Kirchmair L, Entner T, Kapral S, Mitterschiffthaler G. Ultrasound guidance for the psoas compartment block: an imaging study. Anesth Analg 2002; 94: 706-10.

23 Kirchmair L, Enna B, Mitterschiffthaler G, et al. Lumbar plexus in children. A sonographic study and its relevance to pediatric regional anesthesia. Anesthesiology 2004; 101: 445-50.

24 Gray AT, Collins AB, Schafhalter-Zoppoth I. Sciatic nerve block in a child: a sonographic approach. Anesth Analg 2003; 97: 1300-2.

25 Marhofer P, Schrogendorfer K, Koinig H, et al. Ultrasonographic guidance improves sensory block and onset time of three-in-one blocks. Anesth Analg 1997; 85: 854-7.

26 Marhofer P, Schrogendorfer K, Wallner T, et al. Ultrasonographic guidance reduces the amount of local anesthetic for 3-in-1 blocks. Reg Anesth Pain Med 1998; 23: 584-8.

27 Grau T, Leipold R, Conradi R, et al. Ultrasonography and peridural anesthesia. Technical possibilities and limitations of ultrasonic examination of the epidural space (German). Anaesthesist 2001; 50: 94-101.

28 Grau T, Leipold RW, Horter J, et al. Colour Doppler imaging of the interspinous and epidural space. Eur $\mathrm{J}$ Anaesthesiol 2001; 18: 706-12.

29 Gran T, Leipold RW, Horter J, et al. The lumbar epidural space in pregnancy: visualization by ultrasonography. Br J Anaesth 2001; 86: 798-804.

30 Grau T, Leipold RW, Horter J, et al. Paramedian access to the epidural space: the optimum window for ultrasound imaging. J Clin Anesth 2001; 13: 213-7.

31 Gran T, Leipold RW, Conradi R, Martin E. Ultrasound control for presumed difficult epidural puncture. Acta Anaesthesiol Scand 2001; 45: 766-71.

32 Grau T, Leipold RW, Conradi R, et al. Ultrasound imaging facilitates localization of the epidural space during combined spinal and epidural anesthesia. Reg Anesth Pain Med 2001; 26: 64-7.
33 Gran T, Leipold RW, Conradi R, et al. Efficacy of ultrasound imaging in obstetric epidural anesthesia. J Clin Anesth 2002; 14: 169-75.

34 Grau T, Leipold RW, Delorme S, et al. Ultrasound imaging of the thoracic epidural space. Reg Anesth Pain Med 2002; 27: 200-6.

35 Grau T, Leipold RW, Conradi R, et al. The visualisation of dura perforation and blood patches with ultrasound (German). Anasthesiol Intensivmed Notfallmed Schmerzther 2002; 37: 149-53.

36 Grau T, Bartusseck E, Conradi R, et al. Ultrasound imaging improves learning curves in obstetric epidural anesthesia: a preliminary study. Can J Anesth 2003; 50: 1047-50.

37 Gran T, Leipold RW, Fatehi S, et al. Real-time ultrasonic observation of combined spinal-epidural anaesthesia. Eur J Anaesthesiol 2004; 21: 25-31.

38 Marhofer P, Bösenberg A, Sitzwobl C, et al. Pilot study of neuraxial imaging by ultrasound in infants and children. Pediatr Anesth 2005 (in press). 